\title{
Evaluation of Coupling Development for Regional Logistics-Economic System
}

\author{
Yaowu Wang and Zhibin $\mathrm{Lu}^{*}$
}

School of Management, Harbin Institute of Technology, Harbin, Heilongjiang, 150001, China

\begin{abstract}
Regional Logistics-Economic System has been selected as the research object. To solve the collaborative barriers in coupling development of the system, the concept and constitute of Regional Logistics-Economic System have been constructed. The coupling development degree evaluation model and criteria have been established, and a reasonable evaluation index system has been also elected. The coupling development index has been created to measure the coupling development degree of Regional Logistics-Economic System. And the logistics and economic data of Heilongjiang province have been analyzed, the results show the evaluation model and calculation method can be used effectively.
\end{abstract}

Keywords: Coupling development degree, coupling development, regional logistics, regional logistics-economic system (RLES).

\section{INTRODUCTION}

Regional logistics system is an organic entirety that is composed by some dynamic elements which are mutual restraint, such as logistics demand, facilities, resources, information, capital and personnel within the specific scope and area.

The close relationship between regional logistics system and economic system reflects not only the interaction between the two systems directly, but also the conjunctions and coupling among the internal elements in the two systems.

From a higher point of view, regarding the two systems as a unified complex large system, the description and analysis for internal structural are more clear, and the system multiple feedback phenomenon of variables can be dealt effectively.

As a concept of physical, coupling means the influence phenomena was brought by two (more than two) systems or movements interaction effect. Coupling can be considered as two different things turn to a system by mutual promotion, restraint, and linked, that means every subsystems have dynamic association relationship based on interdependence, mutual coordination and promotion.

There's a coupling mechanism between regional logistics and economy. They relate and promote mutually. Zhang wenjie used regional economy theory and transaction cost theory to analyze the relationship between regional logistics and regional economy [1]. Yamaguchi studied Pair Wise Coupling is a popular multi-class classification approach that prepares binary classifiers separating each pair of classes, and then combines the binary classifiers together [2]. Lu Zhibin constructed RLECS model based on SD [3]. Zeng
Wenqi had analyzed the interactive mechanism of regional logistics and economy based on the polar theory of the regional economy [4]. Fan, S. and Zhang Xi used regional economy theory and transaction cost theory to analyze the relationship between regional logistics and regional economy [5]. Gui Shouping, Zhu Qiang, who analyzed the basic causal relationship of the regional logistics system through the system dynamics and established the system dynamics model of the regional logistics [6].

There is no one to study the coupling development between regional logistics and economy system as a complex large system. In this background, as the research object, the comprehensive evaluation model has been established to evaluate the coupling development validity of regional logistics-economic systems.

\section{ANALYSIS OF ORDER PARAMETER FOR RE- GIONAL LOGISTICS-ECONOMIC SYSTEMS}

RLES is a large, open and organic system coordinated by the regional logistics subsystem and regional economic subsystem. They promote, restraint, coupling dynamic, for the co-evolution of logistics and economic [7].

According to Synergetics, in the phase of transition point, the internal variables of system can be divided into two categories, fast and slow relaxation variables. The slow relaxation variable, the order parameter of system is the foremost variable which determines the transition process. The key factor from disorder to order is the synergies action among the order parameters within the system, which affect the feature and law of phase transition [8]. The coupling development degree can measure the degree of synergy. It characterizes the strength of order parameters in the process of interaction synergies.

The order parameter of system is determined by the quality and extent of the order state. Logistics capability is 
Table 1. Indices for order parameters of RLES.

\begin{tabular}{|c|c|c|c|}
\hline Subsystem & Order Parameters & Sub Index & Names of Indices and Measurement Unit \\
\hline \multirow{5}{*}{$\begin{array}{l}\text { Region logistics } \\
\text { system }\end{array}$} & \multirow{5}{*}{ Logistics capability } & $L_{1}$ & Freight Volume (million ton) \\
\hline & & $L_{2}$ & Freight Mileage (hundred million ton kilometer) \\
\hline & & $L_{3}$ & Logistics GDP (hundred million yuan) \\
\hline & & $L_{4}$ & Transport line (kilometer) \\
\hline & & $L_{5}$ & Logistics Investment (hundred million yuan) \\
\hline \multirow{5}{*}{$\begin{array}{l}\text { Region economy } \\
\text { system }\end{array}$} & \multirow{5}{*}{$\begin{array}{l}\text { Level of regional eco- } \\
\text { nomic development }\end{array}$} & $L_{6}$ & Gross Regional Product (hundred million yuan) \\
\hline & & $L_{7}$ & The total social investment in fixed assets (hundred million yuan) \\
\hline & & $L_{8}$ & Total retail sales of consumer goods (hundred million yuan) \\
\hline & & $L_{9}$ & Total volume of import and export trade (hundred million yuan) \\
\hline & & $L_{10}$ & Government receipts (hundred million yuan) \\
\hline
\end{tabular}

selected as the order parameter for regional logistics subsystem. The level of regional economic development is selected as the order parameter of regional economic subsystem. The specific indices are shown as Table $\mathbf{1 .}$

\section{EVALUATION MODEL FOR COUPLING DEGREE OF SYSTEM}

By constructing evaluation model coupling can analysis and evaluate the coupling trends of system. Through anglicizing the coupling mechanism, a theoretical basis can be provided to construct a scientific and rational system coupling development model. Firstly, the coupling degree of subsystems determined. Then, the coupling ratio of each subsystem is compared. If the coupling ratios of the subsystems have similar growth rate, the system achieve the coupling development. If coupling development degree is higher, the development process is more optimizer. On the contrary, it shows that the system does not realize coupling development, or at a low level of coupling development.

\subsection{Calculate the Degree of Order of Subsystem}

Order parameter for each subsystem variables are $u_{i}=\left(u_{i 1}, u_{i 2}, \ldots \ldots, u_{i n}\right)$ and $n \geq 2, \beta i j \leq u i j \leq \alpha i j, j \in[l, n] . \alpha_{i j}$ and $\beta_{i j}$ are upper and lower limits of order parameter on the system stable point. $u_{i 1}, u_{i 2}, \ldots, u_{i n}$ are the numbers of indices which characterize the system operation mechanism and conditions.

$f_{i}\left(u_{i j}\right)$ is defined the order degree of $u_{i j}$, the component of order parameter which is calculated as follows.

$$
f_{i}\left(u_{i j}\right)=\left\{\begin{array}{l}
\frac{u_{i j}-\beta_{i j}}{\alpha_{i j}-\beta_{i j}} \\
\frac{\alpha_{i j}-u_{i j}}{\alpha_{i j}-\beta_{i j}}
\end{array}\right.
$$

Equation (1) shows that $f_{i}\left(u_{i j}\right) \in[0,1]$, and the greater $f_{i}\left(u_{i j}\right), u_{i j}$ is responsible for the larger contribution to the order of system.

$F_{i}$ can be calculated by the integration approach. Based on the characteristics of subsystems, a linear weighted sum method is be used to determine $F_{i}$, shown as equation (2).

$$
F_{i}=\sum_{j=1}^{n} \omega_{j} f_{i}\left(u_{i j}\right) \omega_{j} \geq 0, \sum_{j=1}^{n} \omega_{j}=1
$$

\subsection{Determination of the Index Weight}

The entropy value method is an objective weighting method which is selected to determine the index weight. According to the original information from objective environment, the weight of indices have been determined by analyzing the link extent and information amount of indices of between the indices In this way, it can avoid the deviation caused by subjective factors.

$u_{i j}$ is the value for the $j$-th index of the sample $i,(i=1,2,3$ $\ldots \mathrm{m} ; j=1,2,3, \ldots \mathrm{n})$. The $m$ is the number of samples, and $n$ is the number of indices.

(1) Converting the index weight by formula (3)

$S_{i j}=\frac{\mathrm{u}_{i j}}{\sum_{i=1}^{n} \mathrm{u}_{i j}}$ (4)

(2) Calculating the entropy value of index $u_{i j}$, by formula

$$
h_{j}=-\sum_{i=1}^{n} S_{i j} \ln S_{i j}
$$

(3) Reversing the entropy value by formula (5) $u_{j}=\left\{\begin{array}{cccc}\max h_{j} / h_{j}\left(u_{j} \geq 1\right) & (j=1,2, \ldots, p) & u_{j} \text { is possive index } \\ \min h_{j} / h_{j} & \left(u_{j} \geq 1\right) & (j=1,2, \ldots, p) & u_{j} \text { is negetive index }\end{array}\right.$ 
Table 2. Coupling development criteria.

\begin{tabular}{|c|c|c|c|c|}
\hline & Low coupling & Antagonistic & Break-in & High Coupling \\
\hline \hline Coupling development index & {$[0,0.3)$} & {$[0.3,0.5)$} & {$[0.5,0.8)$} & {$[0.8,1.0]$} \\
\hline
\end{tabular}

(4) Calculating the weights index $u_{j}$ by formula (6)

$$
\omega_{j}=\frac{u_{j}}{\sum_{j=1}^{p} u_{j}}
$$

\subsection{Dimensionless of Indices}

Since many indices have different dimensions, they can not be calculated and compared directly. They must be standardized firstly (dimensionless) to compare with each other. Linear method is being used to process non-dimensional for indices. The calculating equation is shown as formula (7).

$U_{i j}=\left\{\begin{array}{cc}u_{i j} / \max u_{i j} & u_{i j} \text { is possive index } \\ \min u_{i j} / u_{i j} & u_{i j} \text { is negetive index }\end{array}\right.$

\subsection{Calculating the Degree of Coupling Development}

Equation (2) shows that $f_{i}\left(u_{i j}\right) \in[0,1]$, and the greater $f_{i}\left(u_{i j}\right), u_{i j}$ is responsible for the larger contribution to the order of system. And the coupling degree of subsystem is higher, whereas the more low.

Using for reference of physics concepts capacity of the coupling and the capacitance coupling coefficient model, the computing model for the coupling development of system is shown as equation (8).

$C_{n}=\left[\left(\mathrm{F}_{1} \mathrm{~F}_{2} \cdots \mathrm{F}_{\mathrm{m}}\right) / \Pi\left(F_{i}+F_{j}\right)\right]^{n^{n}}$

There are only two subsystems, so the coupling function of RLES can be obtained directly. It is shown as formula (9).

$C_{t}=\left\{\left(F_{1} \bullet F_{2}\right) /\left[\left(F_{1}+F_{2}\right)\left(F_{1}+F_{2}\right)\right]\right\}^{1 / 2}$

$C_{t} \in[-1,1]$, its value is greater the degree of coupling is higher, otherwise lower.

In some cases, the model is difficult to reflect the overall function and level of RLES. For example, the evaluation results of coupling development may be high when the coupling degrees of economic and logistics subsystem are both low. It is unreasonable obviously. Therefore, the coupling development degree is decided by both coupling degree and the level of development. It is represented by $D(t)$

$$
D(t)=\sqrt{C(t) \times F(\mathrm{t})}
$$

$C(t)$ is as a weight coefficient, the modified weighted addition scoring method is be used. $F(t)=\frac{F_{1}(\mathrm{t})+F_{2}(\mathrm{t})}{2} \cdot D(t)$ is the coupling development index in a certain time.

\subsection{Evaluation Criteria for Coupling Development De- gree}

Coupling development index reflects the coupling development level of RLES. It reveals the extent and development level of the system at one time t. It is a quantitative model to measure the coupling development degree. A set of evaluation criteria is need to measure the coupling development level and state.

According to the coupling development index, the coupling development process is divided into low coupling, antagonistic, break-in and high coupling. The specific criteria are shown in Table 2.

\section{EMPIRICAL ANALYSIS}

Heilongjiang Province is the base of heavy industry and foodstuff. And it is an important part of the Northeast Asian economic zone and an important node in the Northeast region and national logistics. The actual data from Heilongjiang Province have been to used to estimates the coupling degree and validate the model and calculation methods.

\subsection{Raw Data Processing and Weight Calculation}

Relevant data of 10 years (2003 to 2012) and 10 indices have been collect, according to the statistical yearbook of Heilongjiang Province.

To determine the best and the worst value is critical, because these two values represent the upper and lower limit. Heilongjiang Province is underdeveloped area, the logistics industry is lower than the national average. The developed area of Shanghai indices has been selected as the best value. The 2003 value of indices from Heilongjiang will be the lower as a starting points for analysis. Specifically indices values are listed in Table $\mathbf{3}$.

The processed Dimensionless raw data and weights are shown as Table 4.

\subsection{Calculating and Analysis the Degree of Order, Cou- pling and Coupling Development}

According to the above evaluation model and indices value, the degree of order, coupling and coupling development can be calculated and obtained. They are shown in Fig. (1).

It can be seen through Fig. (1).

(1) Order degrees of both regional logistics subsystem and regional economic subsystem are increasing year by year. But the order degree of regional logistics subsystem has always lagged behind the economic subsystem. It shows the construction of logistics system behind the economic development in Heilongjiang province. It is because that Heilongjiang Province is located in the national end logistics 
Table 3. Original value and the upper and lower limits.

\begin{tabular}{|c|c|c|c|c|c|c|c|c|c|c|}
\hline \multirow{2}{*}{ Year } & \multicolumn{10}{|c|}{ Index } \\
\cline { 2 - 11 } & $\boldsymbol{L}_{\mathbf{1}}$ & $\boldsymbol{L}_{\mathbf{2}}$ & $\boldsymbol{L}_{\mathbf{3}}$ & $\boldsymbol{L}_{\mathbf{4}}$ & $\boldsymbol{L}_{\mathbf{5}}$ & $\boldsymbol{L}_{\mathbf{6}}$ & $\boldsymbol{L}_{\mathbf{7}}$ & $\boldsymbol{L}_{\mathbf{8}}$ & $\boldsymbol{L}_{\mathbf{9}}$ & $\boldsymbol{L}_{\mathbf{1 0}}$ \\
\hline \hline 2003 & 57491 & 1015.1 & 330.5 & 185725.4 & 136.7 & 4057.4 & 1190.7 & 1376.4 & 441.2 & 531.8 \\
\hline 2004 & 59968 & 1122.0 & 377.1 & 191252.4 & 170.4 & 4750.6 & 1464.7 & 1557.3 & 562.0 & 648.5 \\
\hline 2005 & 64612 & 1180.6 & 331.6 & 195713.40 & 203.7 & 5513.7 & 1731.9 & 1773.8 & 783.9 & 738.3 \\
\hline 2006 & 68880 & 1228.6 & 352.0 & 290196.4 & 246.0 & 6211.8 & 2235.9 & 2029.0 & 1025.2 & 881.5 \\
\hline 2007 & 73122 & 1297.7 & 412.1 & 301104.4 & 309.5 & 7104.0 & 2864.2 & 2386.2 & 1315.5 & 1009.7 \\
\hline 2008 & 56805 & 1704.3 & 434.0 & 322509.4 & 390.0 & 8314.4 & 3656.0 & 2928.3 & 1590.4 & 1295.4 \\
\hline 2009 & 57046 & 1655.8 & 433.6 & 351028.1 & 625.4 & 8587.0 & 5028.8 & 3401.8 & 1108.0 & 1439.5 \\
\hline 2010 & 61950 & 1852.1 & 486.0 & 373300 & 7341 & 10368.6 & 6801.7 & 4078.5 & 1726.2 & 1730.7 \\
\hline 2011 & 66449 & 1984.7 & 568.8 & 410906.2 & 548.2 & 12582.0 & 7475.4 & 4683.2 & 2487.3 & 2373.8 \\
\hline 2012 & 68450 & 2020.8 & 598.8 & 445791.6 & 498.6 & 13691.6 & 9780.2 & 5368.4 & 2442.7 & 3013.5 \\
\hline Upper & 94376 & 20427 & 895.31 & 668536.6 & 771.0 & 20101.3 & 15254.38 & 7412.30 & 28389.6 & 3743.71 \\
\hline Lower & 57491 & 1015.1 & 330.5 & 185725.4 & 136.7 & 4057.4 & 1190.7 & 1376.4 & 441.2 & 531.8 \\
\hline
\end{tabular}

Table 4. Dimensionless values and weights.

\begin{tabular}{|c|c|c|c|c|c|c|c|c|c|c|}
\hline \multirow{3}{*}{ Year } & \multicolumn{10}{|c|}{ Index and Weight } \\
\hline & $L_{1}$ & $L_{2}$ & $L_{3}$ & $L_{4}$ & $L_{5}$ & $L_{6}$ & $L_{7}$ & $L_{8}$ & $L_{9}$ & $L_{10}$ \\
\hline & 0.232 & 0.217 & 0.183 & 0.194 & 0.174 & 0.243 & 0.175 & 0.216 & 0.204 & 0.162 \\
\hline 2003 & 0.60917 & 0.049694 & 0.369146 & 0.277809 & 0.177302 & 0.201848 & 0.078056 & 0.185691 & 0.015541 & 0.142052 \\
\hline 2004 & 0.635416 & 0.054927 & 0.421195 & 0.286076 & 0.221012 & 0.236333 & 0.096018 & 0.210097 & 0.019796 & 0.173224 \\
\hline 2005 & 0.684623 & 0.057796 & 0.370375 & 0.292749 & 0.264202 & 0.274296 & 0.113535 & 0.239305 & 0.027612 & 0.197211 \\
\hline 2006 & 0.729847 & 0.060146 & 0.39316 & 0.434077 & 0.319066 & 0.309025 & 0.146574 & 0.273734 & 0.036112 & 0.235462 \\
\hline 2007 & 0.774794 & 0.063529 & 0.460287 & 0.450393 & 0.401427 & 0.35341 & 0.187762 & 0.321924 & 0.046337 & 0.269706 \\
\hline 2008 & 0.601901 & 0.083434 & 0.484748 & 0.482411 & 0.505837 & 0.413625 & 0.239669 & 0.39506 & 0.056021 & 0.34602 \\
\hline 2009 & 0.604455 & 0.081059 & 0.484302 & 0.525069 & 0.811154 & 0.427186 & 0.329663 & 0.45894 & 0.039028 & 0.384512 \\
\hline 2010 & 0.656417 & 0.090669 & 0.542829 & 0.558384 & 0.95214 & 0.515817 & 0.445885 & 0.550234 & 0.060804 & 0.462295 \\
\hline 2011 & 0.704088 & 0.097161 & 0.635311 & 0.614635 & 0.711025 & 0.62593 & 0.490049 & 0.631815 & 0.087613 & 0.634077 \\
\hline 2012 & 0.72529 & 0.098928 & 0.668819 & 0.666817 & 0.646693 & 0.68113 & 0.64114 & 0.724256 & 0.086042 & 0.80495 \\
\hline
\end{tabular}

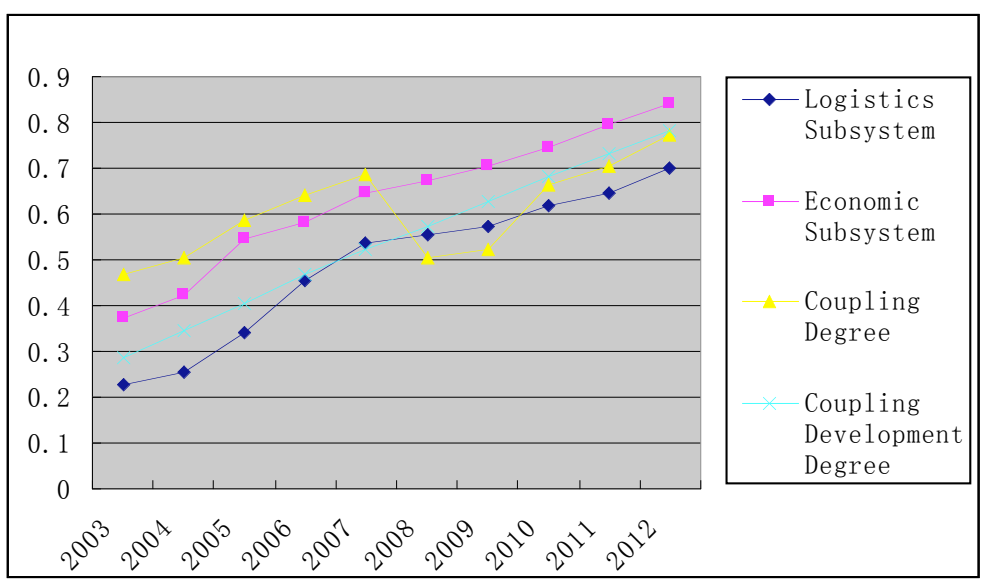

Fig. (1). The degree of order, coupling and coupling development of subsystems. 
network and is consisted with the backwardness of economic in the country.

(2) Except 2008, the financial crisis and slowdown of economic led to the construction of logistics systems and the coupling degree fall down. Coupling degree and coupling development degree of Heilongjiang Province LogisticsEconomic System are still increasing year by year.

(3) Although the coupling development degree is increasing, no more than 0.8 , it indicates that the logistics-economic system in Heilongjiang is still in the break-in stage and has not yet reached a high level of coupling stage. It needs to continue to increase efforts in building and make the logistics system and economy maintain a highly coupled development.

\section{CONCLUSION}

Results of the empirical analysis suggest that the constructed evaluation model for the Heilongjiang Province Logistics-Economic coupling development is in line with the objective reality of the situation. It indicates the overall model and calculation method is effective. Therefore, this method can be further used for other provinces or regions to evaluate the coupling development degree. But the accuracy of the model need to be further refined and improved.

\section{CONFLICT OF INTEREST}

The authors confirm that this article content has no conflict of interest.

\section{ACKNOWLEDGEMENTS}

This work is supported by the Ministry of Education, National Science and Technology Pillar Program (No. 2014BAL05B00).

\section{REFERENCES}

[1] W. Zhang, "Regional economical development and modern logistics," Circulation Economics in China, no. 1, pp. 12-14, 2009.

[2] T. Huang, Z. Zeng, C. Li, and C.S. Leung, "Neural Information Processing," Springer, 2009, pp. 11-20.

[3] Z. Lu, "Coupling development mechanism for regional logisticseconomic complex system based on SD," International Conference on Construction and Real Estate Management, vol. 1, pp. 342-346, 2014.

[4] W. Zeng, "The relations between the development of the regional logistics and the regional economy", Journal of Fujian Administrative College and Institute of Economic Management, vol. 4, pp. 4043, 2010 .

[5] S. Fan, and X. Zhang, "Infrastructure and regional economic development in rural China," China Economic Review, vol. 15, no. 2, pp. 203-214, 2014.

[6] S. Gui, and Q. Zhu "Study of the mechanism of the inventory control based on the system dynamics," Journal of Wuhan University of Technology (Information \& Management Engineering, vol. 1, pp. 20-24, 2012.

[7] Y. Wang, and Z. Lu, "Modelling and simulating for coupling development mechanism of regional logistics-economic complex system", Computer Modelling and New Technologies, vol. 18, no 12, pp. 120-124, 2014.

[8] Z. Lu, "Analysis and construction for city logistics information platform”, Logistics Sci-Tech, vol. 4, pp. 65-66, 2013.

(C) Wang and Lu; Licensee Bentham Open.

This is an open access article licensed under the terms of the (https://creativecommons.org/licenses/by/4.0/legalcode), which permits unrestricted, noncommercial use, distribution and reproduction in any medium, provided the work is properly cited. 